\title{
Prediction and Analysis of Fire Rescue Times Based on ARMA Model
}

\author{
Zhiyuan Wang* \\ Chongqing University of Posts and Telecommunications, College of Automation, Chongqing \\ Municipality, 400065 \\ *Corresponding Author
}

\begin{abstract}
In order to study the prediction and analysis of fire rescue in a certain area, this paper mainly forecasts the number of police calls by establishing a mathematical model, and analyzes the correlation between the area and the incident. Given the number of calls in each month of 2016-2020, we can predict the number of fire rescue calls in each month of 2021 in the future. Because different times are not linearly related to the number of calls, we can establish a model through the time series data of paper [1]. This paper establishes ARMA model to study the law of the development of the number of police calls over time. The accuracy and stability of the model are verified by the data set in 2020, and the number of fire rescue police calls in each month of 2021 is predicted by this model.
\end{abstract}

Keywords: ARMA model, Time series model, Goodness of fit

\section{Introduction}

With the continuous development of science and technology, the national economy has been significantly improved, the complexity of urban space has also increased, all kinds of accidents and disasters occur frequently, and the safety risk is increasing. In particular, fire hazards are often difficult to foresee in advance. Therefore, how to reasonably arrange the fire duty personnel in the city, how to reasonably plan the location and number of fire stations in the city, and whether the fire police personnel can arrive at the fire scene as soon as possible to carry out the rescue work in case of a fire have a great impact on the good development of the city and the good life of the people.

It is assumed that the data of population, area and police records are correct. With the change of time, the population and area of each region have not changed. In case of fire, call the police from the nearest fire station.

\section{The establishment of time series model (ARMA)}

Given the number of calls in each month of 2016-2020, we can predict the number of fire rescue calls in each month of 2021 in the future. Because different times are not linearly related to the number of calls, we can establish a model through the time series data of paper [1]. This paper establishes ARMA model to study the law of the development of the number of police calls over time. The accuracy and stability of the model are verified by the data set in 2020 , and the number of fire rescue police calls in each month of 2021 is predicted by this model.

Based on the data from January 1, 2016 to December 31, 2019, it is required to establish a prediction model for the number of fire rescue calls by month, and take the data from January 1, 2020 to December 31,2020 as the validation data set of the model. 


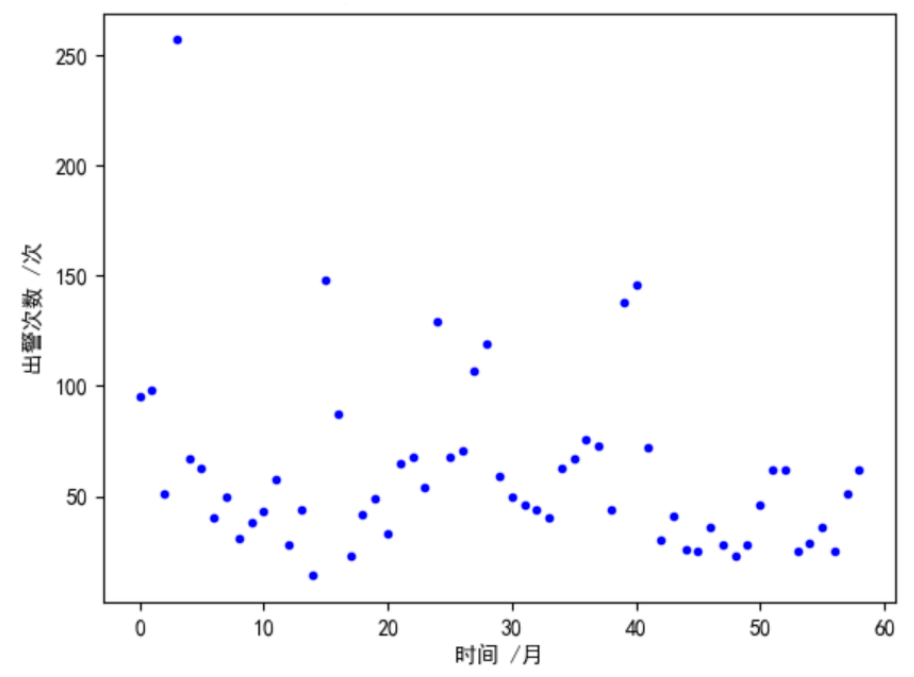

Figure 1: Scatter plot of month and number of police calls

According to the scatter diagram of months and the number of police in 48 months from 2016 to 2019 , we can know that the relationship between time and the number of police is not simple linear. The independent variable is time. With the change of time, the number of police is also changing. Therefore, ARMA time series model can be used to record the change and development process of random events in the order of time to form a time series. By observing and studying the time series, we can find the law of its change and development, and predict the number of police in 2021.

AR (P) model [2]:

$$
\left\{\begin{array}{c}
x_{t}=\phi_{0}+\phi_{1} x_{t-1}+\phi_{2} x_{t-2}+\cdots+\phi_{p} x_{t-p}+\varepsilon_{t} \\
\phi_{p} \neq 0 \\
E\left(\varepsilon_{t}\right)=0, \operatorname{Var}\left(\varepsilon_{t}\right)=\sigma_{\varepsilon}^{2}, E\left(\varepsilon_{t} \varepsilon_{s}\right)=0, s \neq t \\
E x_{s} \varepsilon_{t}=0, \forall s<t
\end{array}\right.
$$

The model with the above structure is called p-order autoregressive model, denoted as AR (P).

MA (q) model:

$$
\left\{\begin{array}{c}
x_{t}=\mu+\varepsilon_{t}-\theta_{1} \varepsilon_{t-1}-\theta_{2} \varepsilon_{t-2}-\cdots-\theta_{p} \varepsilon_{t-p} \\
\theta_{q} \neq 0 \\
E\left(\varepsilon_{t}\right)=0, \operatorname{Var}\left(\varepsilon_{t}\right)=\sigma_{\varepsilon}^{2}, E\left(\varepsilon_{t} \varepsilon_{s}\right)=0, s \neq t
\end{array}\right.
$$

The model with the above structure is called p-order autoregressive model, denoted as MA (q).

$\operatorname{ARMA}(\mathrm{p}, \mathrm{q})$ model:

$$
\left\{\begin{array}{c}
x_{t}=\phi_{0}+\phi_{1} x_{t-1}+\cdots+\phi_{p} x_{t-p}+\varepsilon_{t}-\theta_{1} \varepsilon_{t-1}-\cdots-\theta_{q} \varepsilon_{t-p} \\
\phi_{p} \neq 0, \theta_{q} \neq 0 \\
E\left(\varepsilon_{t}\right)=0, \operatorname{Var}\left(\varepsilon_{t}\right)=\sigma_{\varepsilon}^{2}, E\left(\varepsilon_{t} \varepsilon_{s}\right)=0, s \neq t \\
E x_{s} \varepsilon_{t}=0, \forall s<t
\end{array}\right.
$$

The model with the above structure is called p-order autoregressive model, denoted as ARMA (p,q)

\subsection{Solution based on ARMA model}

The ARMA time series prediction model is used for auto regression to predict the number of police calls from January to December in 2020. The prediction fitting chart is as follows: 


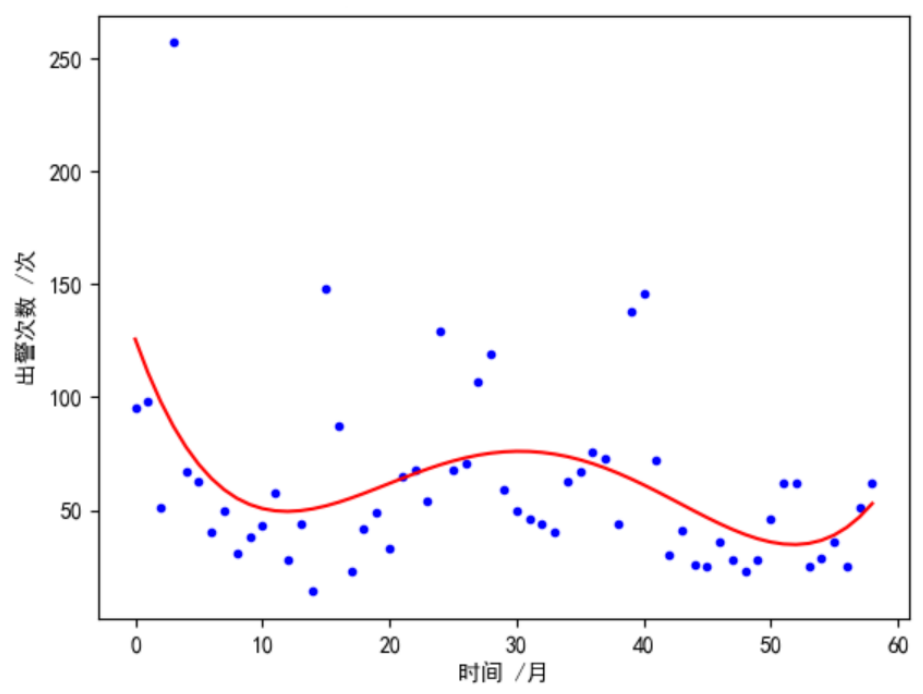

Figure 2: Model validation fire rescue times

\subsection{Accuracy and stability of judgment model}

The ARMA model is established, and the accuracy and stability of the model are tested and analyzed by using the data in 2020 .

(1) Accuracy judgment

$$
\text { Accuracy }=\frac{\text { Estimate }- \text { True value }}{\text { True value }}
$$

Table 1: Forecast value and actual value of the number of police dispatch in 2020

\begin{tabular}{|c|c|c|c|}
\hline Month & True value & Estimate & Accuracy \\
\hline January & 28 & 55.5216 & 0.9829 \\
\hline February & 23 & 66.4002 & 1.8870 \\
\hline March & 28 & 48.8854 & 0.7459 \\
\hline April & 46 & 37.3553 & -0.1879 \\
\hline May & 62 & 115.5564 & 0.8638 \\
\hline June & 62 & 130.5172 & 1.3730 \\
\hline July & 25 & 61.6089 & 1.4644 \\
\hline August & 29 & 7.4681 & -0.7425 \\
\hline September & 36 & 30.1099 & -0.1636 \\
\hline October & 25 & 10.0966 & -0.5961 \\
\hline November & 51 & 4.6410 & -0.9090 \\
\hline December & 62 & 27.3389 & -0.5590 \\
\hline
\end{tabular}

According to the above table, the accuracy of the model is better by comparing the predicted value with the actual value.

(2) Stability test

The ARMA model is used to predict the number of police in 2020 for many times, and the prediction results have no difference, and the stability of the model is good. 


\subsection{Forecast results for 2021}

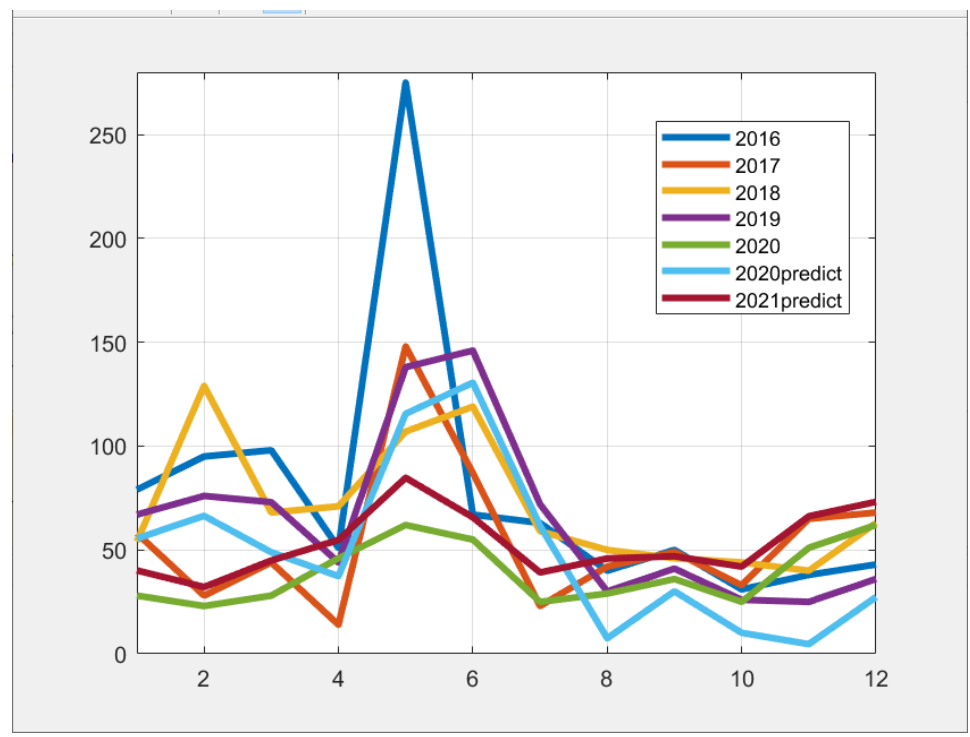

Figure 3: Forecast chart of ARMA model for 2020 and 2021

The figure above shows the forecast results of ARMA model in 2020 and 2021. The forecast data of each month in 2021 are as follows:

Table 2: Monthly forecast data of 2021

\begin{tabular}{|c|c|}
\hline Month & Estimate \\
\hline 2021.1 & 40.1355 \\
\hline 2021.2 & 32.1525 \\
\hline 2021.3 & 44.9197 \\
\hline 2021.4 & 54.7890 \\
\hline 2021.5 & 84.7490 \\
\hline 2021.6 & 65.7067 \\
\hline 2021.7 & 39.1522 \\
\hline 2021.8 & 45.8763 \\
\hline 2021.9 & 46.9618 \\
\hline 2021.10 & 41.9606 \\
\hline 2021.11 & 66.2257 \\
\hline 2021.12 & 73.1634 \\
\hline
\end{tabular}

\section{Summary}

In this paper, we first establish a model based on the data from 2016 to 2019, use the data from 2020 to judge the accuracy and stability of the model, and predict the number of police in 2021. At the beginning, the nonlinear regression model was used to predict, but the accuracy was not high, so the time series model [3] (ARMA) was used to predict.

The model of ARMA time series is used to ensure the stability of the push type and make the influence of initial error disappear gradually. However, nonlinear model is difficult to express the data with high complexity.

\section{References}

[1] Jiang Qiyuan. Mathematical modeling (2nd Edition) [M]. Beijing: Higher Education Press, 1993 [2] Li Daqian. Mathematical modeling contest for Chinese college students (2nd Edition) [M]. Beijing: Higher Education Press, 1998

[3] Han Zhonggeng, mathematical modeling method and its application, 365 pages, higher education press, 2005 